\title{
GAS CHROMATOGRAPHY-MASS SPECTROSCOPY STUDIES ON CESTRUM NOCTURNUM MACERATED METHANOLIC EXTRACT
}

\author{
PRATIP KASHINATH CHASKAR*, SHIVALI HARGOVIND TANK, GAURAV MAHESH DOSHI
}

Department of Pharmaceutical Chemistry, Vivekanand Education Society's College of Pharmacy, Mumbai - 400 074, Maharashtra, India. Email: pratipchaskar@gmail.com

Received: 12 November 2016, Revised and Accepted: 05 December 2016

\section{ABSTRACT}

Objective: Phytochemical screening has revealed the presence of alkaloids, glycosides, carbohydrates, steroids, flavonoids, saponins, and tannins from methanolic extract of Cestrum nocturnum. In this research, we have identified and confirmed the structures of the constituents by gas chromatographymass spectrometry (GC-MS) from the methanolic extract of $C$. nocturnum leaves.

Methods: Shade-dried leaves were powdered and extracted with methanol by cold extraction procedures and the crude extract obtained was used for GC-MS.

Results: There were total five components prominently eluted from C. nocturnum extract, viz., ethyl citrate, phytol, 4-isobutylmorpholine, $n$-hexadecanoic acid, and $\alpha$-amyrin.

Conclusion: GC-MS studies helped to recognize the phytochemical constituents based on their retention time and verification of MS libraries. In future, $C$. nocturnum leaves may be subjected to different extraction procedures and number of elucidating phytoconstituents can be studied for their ethnopharmacological relevance citing the literature.

Keywords: Cestrum nocturnum, Gas chromatography-mass spectroscopy, $\alpha$-Amyrin, $n$-Hexadecanoic acid, Ethyl citrate, Phytol, 4 -Isobutylmorpholine. (C) 2017 The Authors. Published by Innovare Academic Sciences Pvt Ltd. This is an open access article under the CC BY license (http://creativecommons. org/licenses/by/4. 0/) DOI: http://dx.doi.org/10.22159/ajpcr.2017.v10i3.16134

\section{INTRODUCTION}

In recent years, the subject of phytochemistry has immensely helped in narrowing the gap between natural products and organic chemistry by providing their proper identification and elucidation. Application of hyphenated techniques (such as liquid chromatography-mass spectroscopy-, gas chromatography-MS (GC-MS), and fast atom bombardment-MS [1] helped to determine the nature of plants and their different phytoconstituents on the basis of different methods of separation, purification, and identification of phytoconstituents [2]. Phytochemical progress has been regarded to play a key role in the development of rapid and accurate methods selected for screening various plants particularly phytoconstituents which have got ethnopharmacological relevance in the herbal industries as well as those beneficial to mankind [3].

It has been known that plethora of plant phytoconstituents belonging to the class of terpenoids have been noticed down due to the presence of biosynthetic origin and isoprene molecules (made up of union of two or more C-5 units) formed from the in vivo precursor isopentenyl pyrophosphate. Each class of terpenoid has significance in regulating plant growth, metabolism and maintaining ecology balance. Triterpenoids are compounds having six carbon skeletons and are based as isoprene units which are thought to be derived biosynthetically from the acyclic C-30 hydrocarbon, squalene. True triterpenes, steroids, saponins, and cardiac glycosides are the four classes of the triterpenoids. The triterpenes or steroids are thought to be existing in the form of glycosides. Sterols and triterpenes are compounds of cyclopentane perhydrophenanthrene ring system $[1,4]$.

Pentacyclic triterpenes, such as $\alpha$-amyrin and $\beta$-amyrin, have been experiencing for their immense biological effects. These components are noticed in bark incisions of numerous species of bursera or protium. They are used as a protective function in combating insects and microorganisms from attacking the fruits. Triterpenes are also found to be present in resins, barks and in latex of euphoria, hevea, etc. Common families of plants belonging to the class of triterpenes comprise of Rutaceae, Meliaceae, Simaroubaceae, and Cucurbitaceae. $\alpha$-amyrin is reported to be found in mexican copal, Cassia obtusifolia, resin of Commiphora holtziana, etc. [5-7].

Cestrum nocturnum Linn. is found as a shrub in tropical America and is cultivated as an ornamental plant in India. The leaves are simple, narrow lanceolate, smooth, and glossy with an entire margin. Saponins, glycosides, alkaloids, ursolic acids, and chlorogenic acids are the major chemical constituents responsible for therapeutic potential. It is employed in perfumes and imparting fragrance, as mosquito repellant and treatment for night sweats $[8,9]$.

The separation and purification of phytoconstituents are carried out using one single method or combination of methods. The choice and selection of technique relies heavily on the solubility properties and volatilities of the phytoconstituents to be determined and separated. GC has its important application in identification of volatile components, fatty acids, mono and sesquiterpenes, hydrocarbons and sulfur compounds. GC provides both quantitative as well as qualitative identification of plant constituents [1]. The GC apparatus can be coupled with MS for spectral analysis. In the last few years, GC-MS has emerged out as one of the most important hyphenated and advanced technique that is useful in the identification of plants constituents. Although the researchers have identified various components from the extract, this research focuses on structural elucidation and categorization of various phytoconstituents from the leaves of $C$. nocturnum by GC-MS. 


\section{METHODS}

Collection, authentication, extraction, and preliminary phytochemical screening

The $C$. nocturnum leaves have been collected, authenticated, extracted, and subjected to preliminary phytochemical screening as reported previously by the researcher [10-12].

\section{GC-MS studies on methanolic extract of $C$. nocturnum leaves}

Methanol was invoked as the mobile phase. Electron impact - MS (EI-MS) spectrum was scanned at $70 \mathrm{eV}$ with Joel instrument of model Accu time of flight analyzer GCV. Mass range used was 10-2000 amu and resolution of 6000 . The make of GC was Agilent 7890. Flame ionization detector was used as a detector having a run time of $40 \mathrm{~min}$. GC-MS analysis was performed by splitless injection of $1.0 \mu \mathrm{L}$ of the sample in methanol on a Hewlett Packard 6890 (USA) gas chromatograph fitted with a cross-linked $5 \%$ phenylmethylsiloxane HP-5 MS capillary column $(30 \mathrm{~m} \times 0.32 \mathrm{~mm} \times 0.25 \mu \mathrm{m}$ coating thickness), coupled with a mass detector. GC-MS operating conditions were as follows: Injector temperature $215^{\circ} \mathrm{C}$, transfer line $280^{\circ} \mathrm{C}$, oven temperature programme $80-280^{\circ} \mathrm{C}$ with ramping $5^{\circ} \mathrm{C}$ per min, carrier gas: Helium at $1.5 \mathrm{~mL} / \mathrm{min}$, $\mathrm{EI}^{+}$, individual components were identified by NIST MS 2.0 structural library.

\section{RESULTS AND DISCUSSION}

Plant terpenoids are commonly known for their separate functions as growth regulators and as accessory pigments in phytoconstituents. The class of triterpenes signifies vital ethnopharmalogical prospects in multiple pathological diseases [1,5]. In this contemporary research

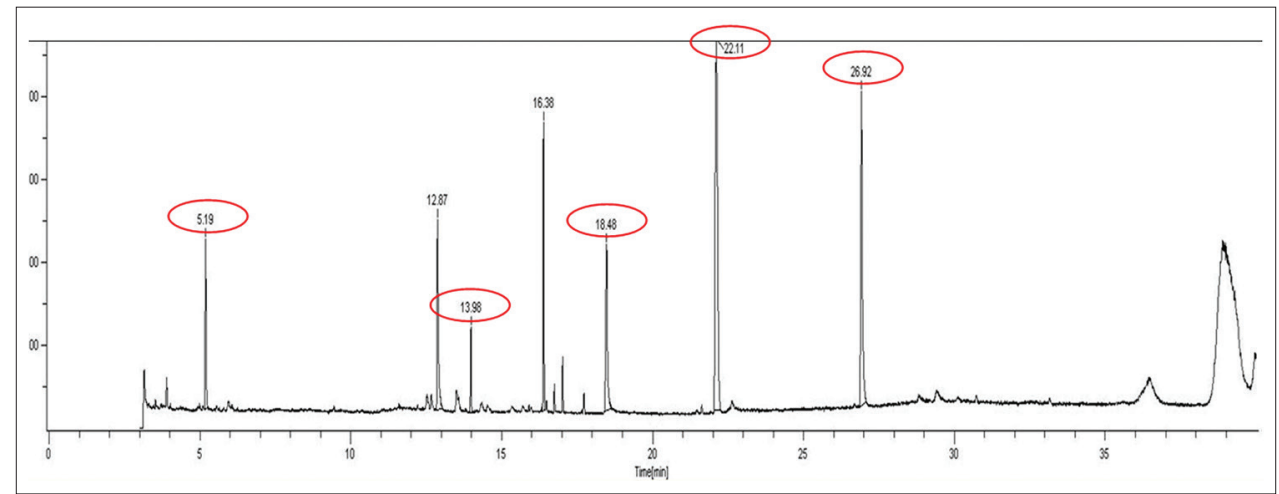

Fig. 1: Gas chromatography-mass spectrometry chromatogram of methanolic extract of Cestrum nocturnum

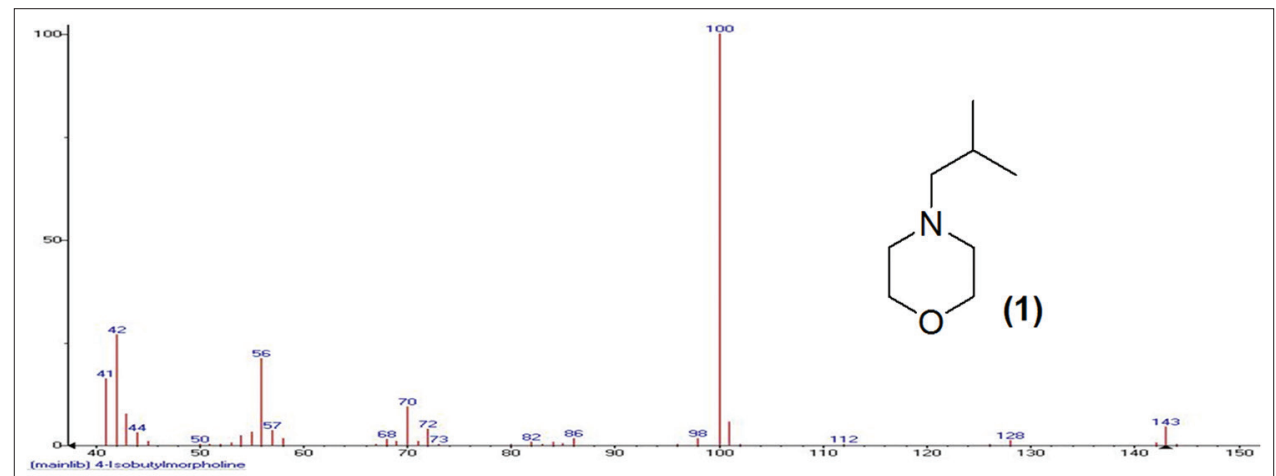

Fig. 2: Gas chromatography-mass spectrometry spectrum of 4-Isobutylmorpholine (1) with $m / z 143$

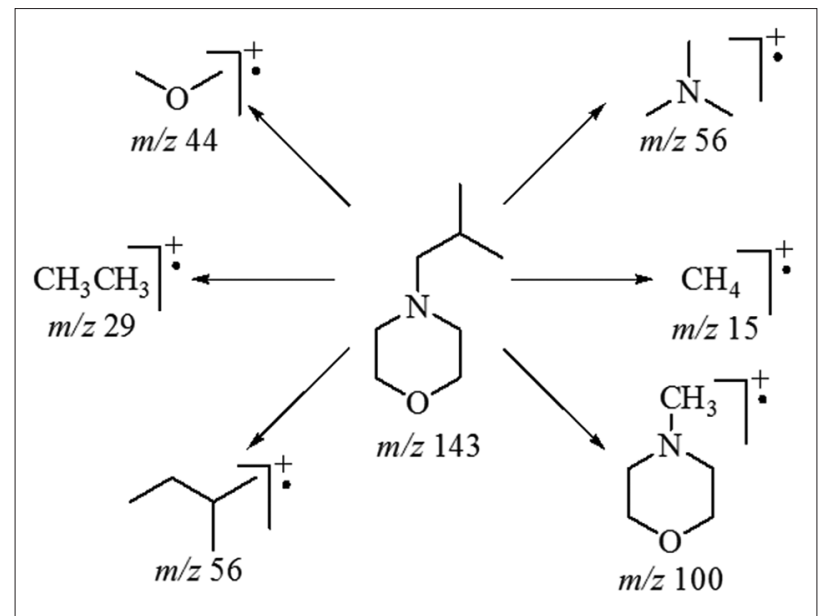

Scheme 1: Fragmentation pattern of 4-isobutylmorpholine $(1)(m / z 143)$ with fragments $m / z 15,29,44,56,100$ 
Table 1: Various components and their fragments in methanolic extract of $C$. nocturnum extract

\begin{tabular}{|c|c|c|c|c|}
\hline $\begin{array}{l}\text { Retention } \\
\text { time }\end{array}$ & Identity & $\begin{array}{l}\text { Molecular } \\
\text { formula }\end{array}$ & $m / z$ & Synonyms \\
\hline 5.19 & (1) & $\mathrm{C}_{8} \mathrm{H}_{17} \mathrm{NO}$ & 143 & 4-Isobutylmorphine \\
\hline 13.98 & (2) & $\mathrm{C}_{12}^{8} \mathrm{H}_{20} \mathrm{O}_{7}$ & 276 & $\begin{array}{l}\text { 1,2,3-Propanetricarboxylic acid, 2-hydroxytriethyl ester, citroflex 2, triethyl citrate, triethylester } \\
\text { kyseliny citronove, 2-hydroxy-1,2,3-propane tricarboxylic acid, triethyl ester, crodamol } \\
\text { TC, ethyl citrate, citric acid triethyl ester, hydagen C.A.T, unilflex tec, uniplex 80, triethyl } \\
\text { 2-hydroxy-1,2,3-propanetricarboxylate }\end{array}$ \\
\hline 18.48 & (3) & $\mathrm{C}_{16} \mathrm{H}_{32} \mathrm{O}_{2}$ & 256 & $\begin{array}{l}\text { Palmitic acid, cetylic acid, } n \text {-hexadecanoic acid, hexadecylic acid, hydrofol, } n \text {-hexadecoic acid, } \\
\text { 1-pentadecanecarboxylic acid, hexaectylic acid, pentadecanecarboxylic acid, industrene } 4516 \text {, } \\
\text { emersol 140, emersol 143, hystrene 8016, hystrene 9016, prifac } 2960 \text {, glycon p- } 45 \text {, univol U } 332\end{array}$ \\
\hline 22.11 & (4) & $\mathrm{C}_{20} \mathrm{H}_{40} \mathrm{O}$ & 296 & $\begin{array}{l}\text { 2-Hexadecen-1-ol, 3,7,11,15-tetramethyl, trans-phytol, \#, } \\
\text { 7,11,15-tetramethyl-2-hexadecen-1-ol, }(2 E) \text {-3,7,11,15-tetramethyl-2-hexadecen-1-ol }\end{array}$ \\
\hline 26.92 & (5) & $\mathrm{C}_{18} \mathrm{H}_{31} \mathrm{ClO}$ & 426 & Urs-12-en-3-ol, $(3 \beta)$, Urs-12-en-3 $\beta$-ol, $\alpha$-amyrenol, $\alpha$-amyrine, viminalol, Urs-12-en-3-ol \\
\hline
\end{tabular}

C. nocturnum: Cestrum nocturnum

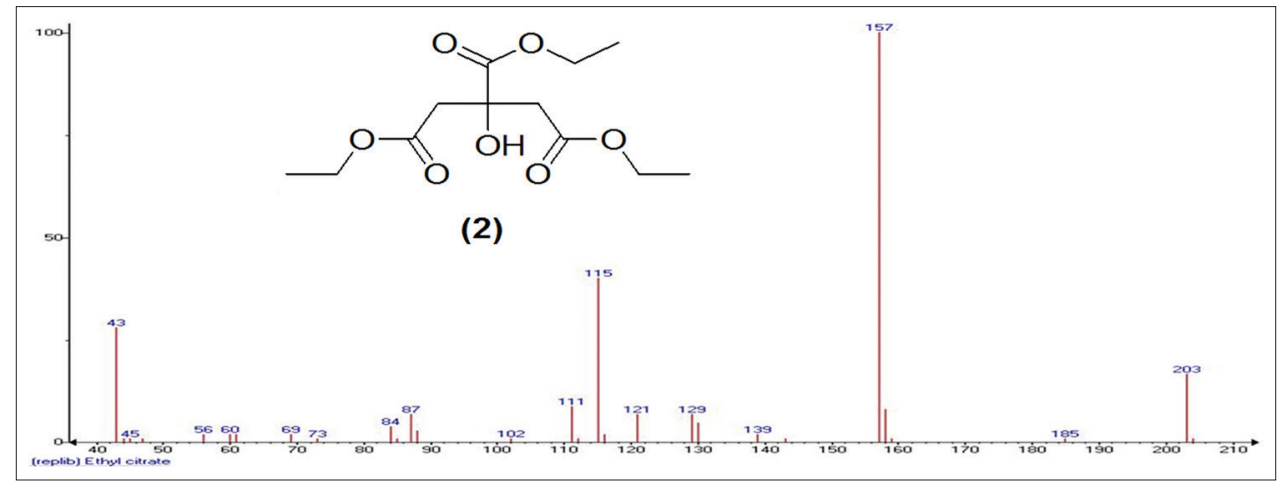

Fig. 3: Gas chromatography-mass spectrometry spectrum of ethyl citrate (2) with $\mathrm{m} / \mathrm{z} 276$

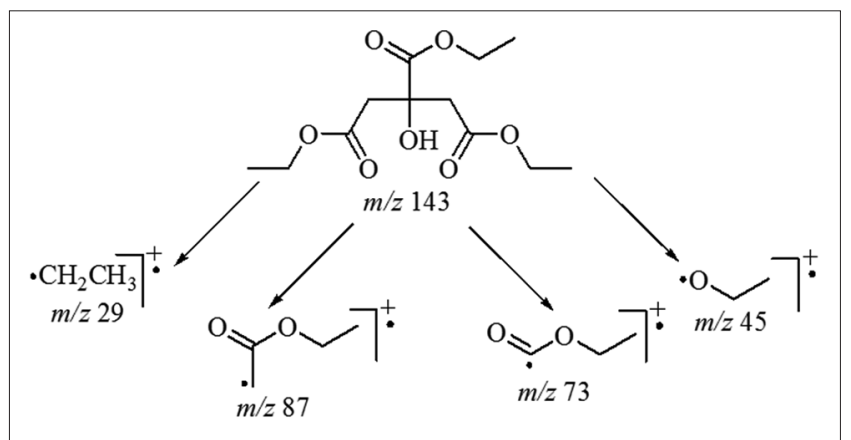

Scheme 2: Fragmentation pattern of ethyl citrate (2) $(m / z 276)$ with fragments $m / z 29,45,73,87$

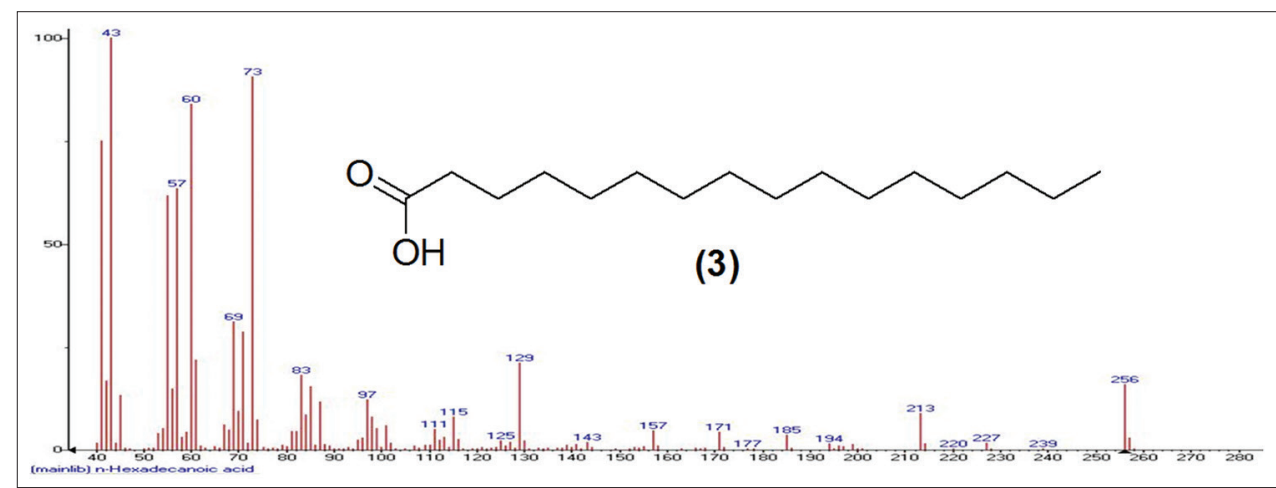

Fig. 4: Gas chromatography-mass spectrometry spectrum of n-hexadecanoic acid (3) with $\mathrm{m} / \mathrm{z} 256$

article, five components were identified by GC-MS technique as revealed in MS of the extract as depicted in Fig. 1 with their retention times showed in Table 1.
The components stated in Table 1 of $C$. nocturnum extract were found to be 4-Isobutylmorpholine (1), ethyl citrate (2), $n$-hexadecanoic acid (3), phytol (4), and $\alpha$-amyrin (5) (Figs. 2-6 and Schemes 1-5). 


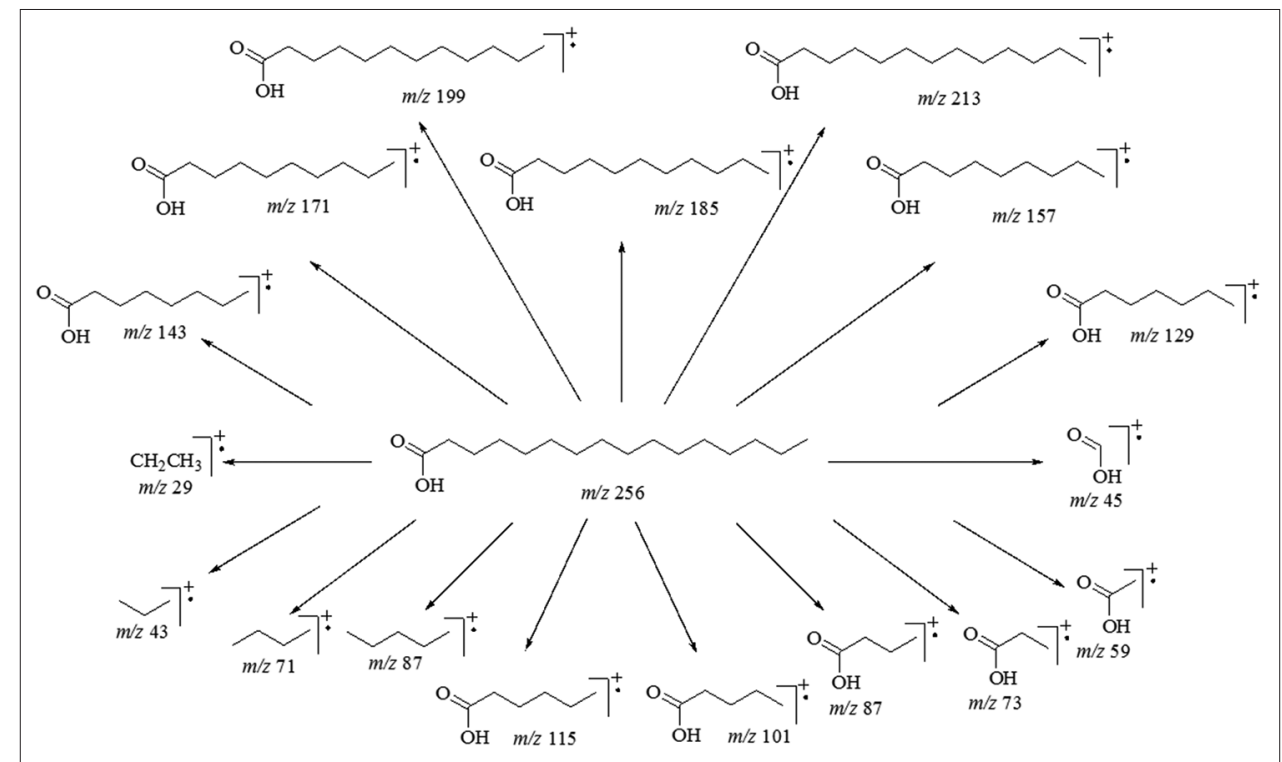

Scheme 3: Fragmentation pattern of $n$-hexadecanoic acid $(3)(m / z 256)$ with fragments $m / z 29,43,45,59,71,73,87,101,115,129,143$, $157,171,199,213$

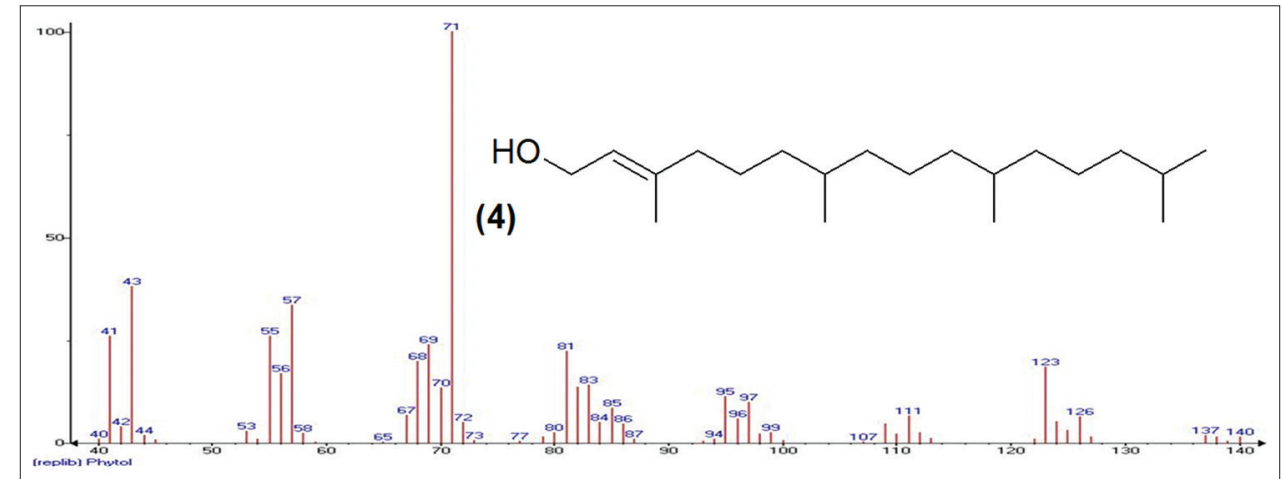

Fig. 5: Gas chromatography-mass spectrometry spectrum of phytol (4) with $m / z 296$

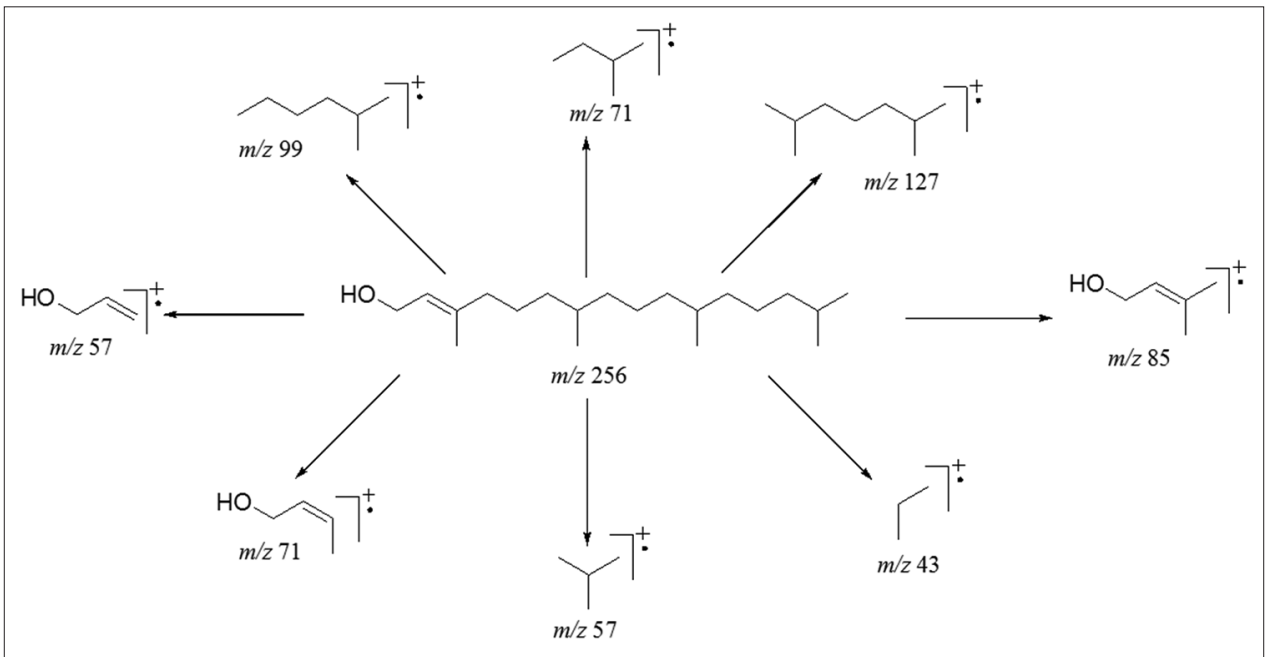

Scheme 4: Fragmentation pattern of phytol (4) (m/z 296) with fragments $m / z$ 43, 57, 71, 85, 99, 127

To categorize the phytoconstituents, we subjected the extract to GC-MS analysis in which 4-isobutylmorpholine (1), ethyl citrate (2), $n$-hexadecanoic acid (3), phytol (4), and $\alpha$-amyrin (5) were found to be significant the extract. They were designated by comparing their MS spectra to those of standard spectra from the
NIST library. 4-Isobutylmorpholine is being used to a large extent as a reagent in the pharmaceutical industry. Ethyl citrate is invoked as a pseudo-emulsifier in e-cigarette juices, food products and as a plasticizer [13]. Antioxidant, hypocholesterolemic, nematicide, insecticide, lubricant, and hemolytic properties are exhibited by 


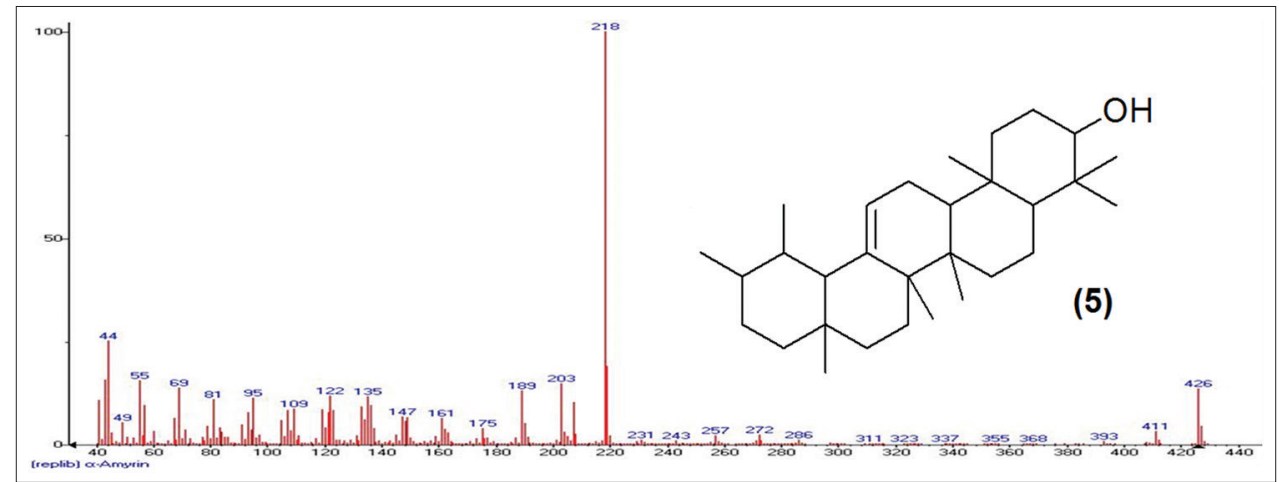

Fig. 6: Gas chromatography-mass spectrometry spectrum of $\alpha$-amyrin (5) with $m / z 426$

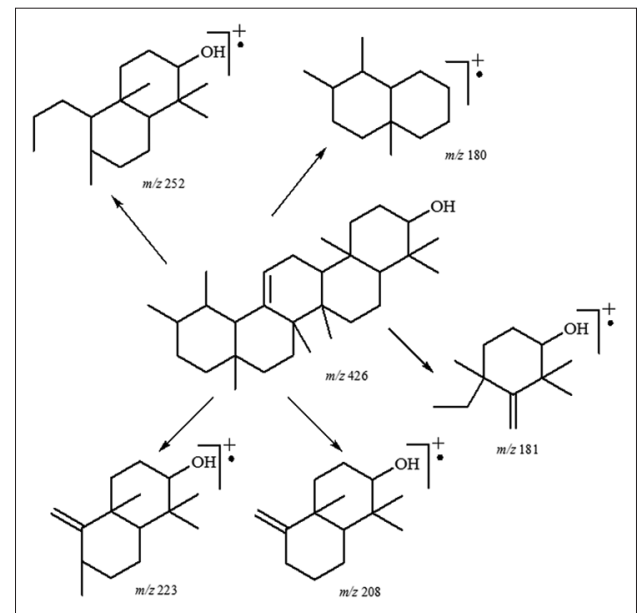

Scheme 5: Fragmentation pattern of $\alpha$-amyrin (5) $(m / z$ 426) with fragments with $m / z 43,44,55,60,122,189,203,218,219,426$

$n$-hexadecanoic acid [14]. Phytol has been tried and found to be a potent antimycobacterial agent and in cosmetics, shampoos, toilet soaps, household cleaners, and detergents [15]. $\alpha$-amyrin is reported to have an ameliorative effect on infectious diseases [16]. These phytoconstituents categorized suggest that the plant is a rich source of many bioactive compounds which can be evaluated further for numerous pharmacological potential.

\section{CONCLUSION}

The paper on macerated methanolic $C$. nocturnum extract leaves would probably help the phytochemistry based scientists and researchers for scrutinizing the elucidated components for particular pharmacological significance in the near future based on the research statistics. In addition, research can be elaborated and focused on numerous different extraction procedures and elucidation and comparison of various phytoconstituents by application of various chromatographic hyphenated techniques.

\section{ACKNOWLEDGMENT}

We would like to thank the college management who provided us all the facilities to carry out the extraction work. We would also like to acknowledge SAIF Department, GC-MS Laboratory, Indian Institute of Technology, Mumbai, for their assistance.

\section{REFERENCES}

1. Harborne JB. In: Phytochemical Methods. $3^{\text {rd }}$ ed. New Delhi: Springer Publication House; 2005. p. 1-295.

2. Buckingham J. In: Dictionary of Natural Products. $1^{\text {st }}$ ed. London: Chapman and Hall; 1994. p. 640-6.

3. Samuelsson G. In: Drugs of Natural Origin. $5^{\text {th }}$ ed. Sweden: Swedish Pharmaceutical Press; 2004. p. 154-5.

4. Doshi GM, Nalawade VV, Mukadam AS, Chaskar PK, Zine SP,
Somani RR et al. Structural elucidation of chemical constituents from Benincasa hispida seeds and Carissa congesta roots by Gas chromatography - mass spectroscopy. Pharmacognosy Res 2015;7(3):282-93.

5. Vazquez LH, Palazon J, Ocana AN. In: Phytochemicals. Vienna: InTech Publishers; 2012. p. 487-502.

6. Hegnauer R. In: Waterman PG, Grundon MF, editors. Chemistry and Chemical Taxonomy of the Rutales. London: Academic Press; 1983. p. 401-40.

7. Hill RA. In: The Chemistry of Natural Products. London: Blackie Academic \& Professional; 1993. p. 106-39.

8. Anonymous. In: The Wealth of India. New Delhi, India: Council of Scientific \& Industrial Research; 1950. p. 125-8.

9. Warrier PK, Nambiar VPK, Ramankutty C. In: Indian Medicinal Plants. New Delhi, India: Orient Longman Private Limited; 1976. p. 224-34.

10. Kokate CK. In: Practical Pharmacognosy. New Delhi, India: Vallabh Prakashan; 1989. p. 111-25.

11. Khandelwal KR. In: Practical Pharmacognosy. $10^{\text {th }}$ ed. New Delhi, India: Nirali Prakashan; 2003. p. 149-56.

12. Doshi GM, Mukadam AS. Pharmacognostic quantification of flavonoids by high performance thin layer chromatography and in vitro cell line study on developed herbal formulation from Cestrum nocturnum plant extract. Int J Green Pharm 2016;10(3):183-92.

13. Park HM, Misra M, Drzal LT, Mohanty AK. Green nanocomposites from cellulose acetate bioplastic and clay: Effect of eco-friendly triethyl citrate plasticizer. Biomacromolecules 2004;5(6):2281-8.

14. Selvarani K, Stella Bai GV. GC-MS analysis of biologically active compounds in Cayratia pedata (Lam) leaf and callus extracts. Int J Chem Stud 2014;2(3):51-6.

15. Sahoo S, Jena S, Sahoo A, Ray A, Nasim N, Kar N, et al. GC-MS analysis and evaluation of bioactivities of Kaempferia parishii - A natural source of totarol. Int J Pharm Pharm Sci 2016;8(5):182-6.

16. Venkatachalapathi A, Paulsamy S, Thambiraj J. Antimicrobial efficacy of the ethnomedicinal plant species, Canarium strictum Roxb. Int J Pharm Pharm Sci 2016;8(2):339-41. 